\title{
ANTITERMITIC EFFECTS OF THREE WOOD STAIN TREATMENTS
}

\author{
Cihat Tascioglu $^{1^{*}}$, Mehmet Budakct ${ }^{2}$, Tsuyoshi Yoshimura ${ }^{3}$
}

\author{
In memoriam of Dr. Manfred SCHWANNINGER
}

\begin{abstract}
Potential antitermitic properties of some common wood stains were tested against Coptotermes formosanus. Four different wood species treated with 3 different stain chemicals at the $0,1 \mathrm{~kg} / \mathrm{m}^{2}$ retention level were exposed to no-choice termite feeding test in laboratory conditions. Mean mass loses, mortality rates and consumption rates were calculated based on weight changes before and after the test. While the hardwood species (beech and chestnut) tested were unaffected by the treatments, the softwood species tested showed drastically reduced mass losses with some stain treatments. Scots pine and spruce sapwood exhibited significant reductions in mass losses when treated with the chemical stain.
\end{abstract}

Key words: Wood stain, Coptotermes formosanus, treatment, antitermitic.

\section{INTRODUCTION}

Wood extractives give distinctive color to various wood species. Furthermore, hemicelluloses and lignin darken wood surfaces with time due to oxidation effects. In furniture and decoration applications, it is considered very difficult to match colors and shades of wood material even if it is taken from the same $\log$ (Newel and Holtrop 1961, Sonmez et al. 2003).

Wood color also plays an important role determining its economic value (Ishiguri et al. 2003). In addition, color harmony is considered an important aspect in furniture manufacturing and interior decoration (Sonmez 2005, Flexner 2005). In most cases, wood staining (coloring) is required to change wood color in order to meet the end-users' preferences.

The basic function of such colorants is to change color without diminishing the grain pattern of wood or forming a protective layer on wood surface (Gardner et al. 2003). It is well known that solid wood needs to be protected against wood destroying organisms (decay fungi, insects, termite etc.) if indented to be used in outdoor applications. Unfortunately, the protective effects of wood staining chemicals have not been studied, especially with regards to effects upon termite activity. Based on this background, the research on antitermitic properties three common wood stain chemicals is described.

\footnotetext{
' Department of Forest Biology and Wood Preservation Technology, Faculty of Forestry, Duzce University, Duzce, Turkey

${ }^{2}$ Department of Wood Works Industrial Engineering, Faculty of Technology, Duzce University, Duzce, Turkey

${ }^{3}$ Research Institute of Sustainable Humanosphere (RISH), Kyoto University, Gokasho, Uji, 611 0011, Kyoto, Japan

^Corresponding author: cihattascioglu@duzce.edu.tr

Received: 12.03. 2013 Accepted: 23.09. 2013
} 


\section{Wood Material}

\section{MATERIALS AND METHOD}

Four different wood species, Beech (Fagus orientalis L.), Chestnut (Castanea sativa Mill), Scots pine (Pinus sylvestris L.) and Spruce (Picea orientalis Link.), commonly utilized in the furniture industry in Turkey, were used in this study. Specimens were cut $20 \times 20 \times 10 \mathrm{~mm}$ in size from randomly selected Beech, Chestnut, Scots pine and Spruce sapwood lumber showing no spiral grain, knots or discoloration with minimal variation in density. The mean oven dried densities of the wood species were 630,590 , 490 and $400 \mathrm{~kg} / \mathrm{m}^{3}$ for Beech, Chestnut, Scots pine and Spruce, respectively.

\section{Wood Stains}

Three different wood stains, aniline, chemical $\left[\operatorname{tannin}\left(\mathrm{C}_{14} \mathrm{H}_{10} \mathrm{O}_{9}\right)+\right.$ potassium dichromate $\left(\mathrm{K}_{2} \mathrm{Cr}_{2} \mathrm{O}_{7}\right)$ ] and Van Dyke brown, were used in this experiment. The sample color was determined as walnut (brown). Formulation and application details of wood stains are given in table 1.

Table 1. Formulations and application details of wood stains used.

\begin{tabular}{|l|lll|lll|}
\hline \multicolumn{5}{|c|}{ Stains } \\
\hline \multicolumn{1}{|c|}{ Aniline } & \multicolumn{3}{|c|}{ Chemical } & \multicolumn{3}{c|}{ Van Dyke brown } \\
\hline Aniline 5\%* & $\mathrm{C}_{14} \mathrm{H}_{10} \mathrm{O}_{9}$ & $5 \%$ (first stain) & 6 unit Van Dyke brown $\left(\mathrm{Fe}_{2} \mathrm{O}_{3}, \mathrm{MnO}_{2}\right)$ & $10 \%$ \\
$\left(\mathrm{C}_{6} \mathrm{H}_{2} \mathrm{NH}_{2}\right)$ & $\mathrm{K}_{2} \mathrm{Cr}_{2} \mathrm{O}_{7}$ & $5 \%$ & (second stain) & 3 unit & $\mathrm{K}_{2} \mathrm{Cr}_{2} \mathrm{O}_{7}$ & $5 \%$ \\
& & & & 1 unit & $\mathrm{NH}_{3}$ & $35 \%$ \\
\hline
\end{tabular}

*: $1 \mathrm{~L}$, distilled water; $50 \mathrm{~g}$, pigment dissolved.

Aniline $\left(\mathrm{C}_{6} \mathrm{H}_{2} \mathrm{NH}_{2}\right.$, also known as phenylamine or aminobenzene) is heavily utilized in the rubber processing industry, as a dye and pigment, and is also used as a precursor to indigo stain and herbicides. Chemical stain is a two-stage staining process commonly used in the furniture industry. Van Dyke brown consists of $\mathrm{Fe}_{2} \mathrm{O}_{3}, \mathrm{MnO}_{2}$ and humic acid and is often used for staining woods and glazes on prints. All stains were applied via an application brush until the specimens reached a surface retention level of $0,1 \mathrm{~kg} / \mathrm{m}^{2}$. After 2 minutes to allow for surface wetting, the excessive stain was removed with a clean sponge. All anatomical directions (radial, tangential and cross sections) of wood received the treatment. Since Scots pine, Spruce and Beech wood contain no or a slight amount of tannin, the chemical staining was applied in two stages. In the first step, $5 \% \mathrm{C}_{14} \mathrm{H}_{10} \mathrm{O}_{9}$ solution was applied on the wood surfaces. After 24 hours of diffusion time at ambient conditions (at $22^{\circ} \mathrm{C}$ ), $5 \% \mathrm{~K}_{2} \mathrm{Cr}_{2} \mathrm{O}_{7}$ was applied as a second step. Chestnut wood, on the other hand, was stained in one step with $5 \%$ of $\mathrm{K}_{2} \mathrm{Cr}_{2} \mathrm{O}_{7}$ due to its higher natural tannin content.

\section{Termite resistance test}

The antitermitic performance of the stained specimens was evaluated according to the Japanese Wood Preservers Association method (JWPS-TW-P.1 2001). Five replicate samples ( 20 x 20 x 10mm) for each retention level were randomly selected for the termite test. Individual samples were exposed to 150 workers and 15 soldiers of Coptotermes formosanus Shiraki (Blattodea:Rhinotermitidae) at $28 \pm 2^{\circ} \mathrm{C}$ and above $80 \%$ RH for 21 days in the dark. The details of termite test setup are given in figure 1 . 


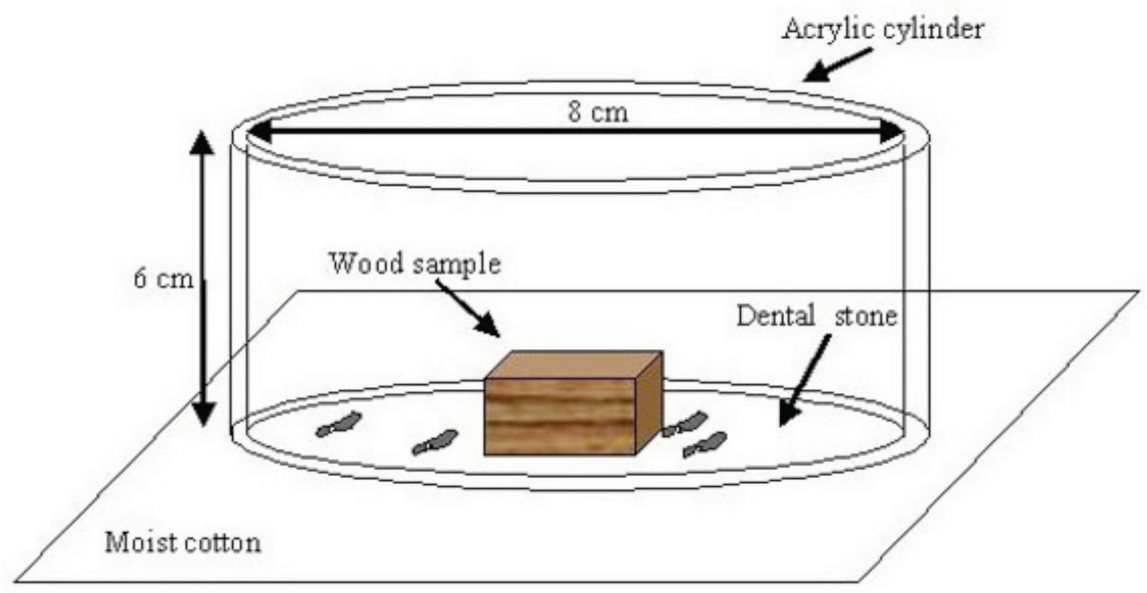

Figure 1. No-choice feeding test setup for wood block (JIS).

The percent of mass loss of each test specimen was calculated from the difference in oven-dried weights before and after the termite test. Termite mortality and consumption rates were also calculated. Wood consumption rates, which indicate how much wood is eaten by individual termites over a desired period (e.g. $\mu \mathrm{g} /$ termite/day), were determined from data on termite mortality and wood consumption rates by termites according to the assumption that termite mortality developed linearly during the termite test.

\section{Statistical analyses}

All results were evaluated using SPSS statistical tool (SPSS 19, 2010). One-way analysis of variance and Duncan's tests were used to evaluate changes in mass loss, mortality and consumption rate and to rank their mean values.

\section{RESULTS AND DISCUSSION}

As shown in table 2, the wood species gave different mean mass loss results depending on their natural durability and the wood stains applied. In general, hardwood species (Beech and Chestnut) resulted in relatively low mass losses when compared to the mass losses of the softwood specimens tested (Scots pine and Spruce). These findings are consistent with previous studies in the literature indicating that density may have an influence on mass loss and consumption rates (Esenther 1977, Peralta et al. 2004, Arango et al. 2004, Arango et al. 2006).

Table 2. Mean mass loss [ML (\%)] of stained woods after exposure to Coptotermes formosanus for 3 weeks.

\begin{tabular}{|c|r|c|c|c|}
\hline \multirow{2}{*}{ Treatments } & \multicolumn{5}{|c|}{ Wood species } \\
\cline { 2 - 6 } & Beech & Chestnut & Scots pine & Spruce \\
\hline Control & $8,7(1,70) \boldsymbol{a}$ & $2,9(0,85) \boldsymbol{a}$ & $10,3(0,38) \boldsymbol{c}$ & $40,7(3,19) \boldsymbol{c}$ \\
\hline Aniline & $8,0(1,84) \boldsymbol{a}$ & $3,7(0,53) \boldsymbol{a} \boldsymbol{b}$ & $8,0(0,93) \boldsymbol{b}$ & $9,8(1,66) \boldsymbol{a}$ \\
\hline Chemical & $5,6(2,23) \boldsymbol{a}$ & $5,0(0,71) \boldsymbol{b}$ & $1,6(0,24) \boldsymbol{a}$ & $9,3(1,42) \boldsymbol{a}$ \\
\hline $\begin{array}{c}\text { Van Dyke } \\
\text { brown }\end{array}$ & $7,5(3,37) \boldsymbol{a}$ & $4,5(0,85) \boldsymbol{b}$ & $11,0(0,23) \boldsymbol{c}$ & $15,9(1,23) \boldsymbol{b}$ \\
\hline
\end{tabular}

mean of 5 specimens - numbers in parentheses are standard deviations

*means within each column followed by the same letter are not significantly different, $\mathrm{p}<0.05$ (Duncan's test). 
The stain chemicals applied did not help to reduce mass loss in hardwood species (Beech and Chestnut), in some cases mass loses were even higher than the mass loss of unstained control specimens. This might be explained with anatomical features and lower permeability of hardwoods tested. Since no vacuum or pressure were applied in the staining process only capillary forces played a role in penetration of the stain chemicals. As documented elsewhere the effective diameter pit openings, which stain particles use to move from one tracheid to another with help of carrier fluid, were measured between $0.02-4 \mu \mathrm{m}$ and 5-170 $\mathrm{nm}$ for softwoods and hardwoods, respectively (Siau 1995). This approximately thousand-fold difference in pit openings certainly helps deeper penetration of stain particles in softwoods, and may hamper penetration in hardwoods resulting unprotected zones in the wood blocks. Furthermore, the high tannin content of Chestnut wood might contribute to its natural durability resulting in low mass loss when exposed to termite activity (Vazquez et al. 2009). Softwood species, on the other hand, showed 84,5\% and $77,1 \%$ mass loss reductions when treated with tannin stain for Scots pine and Spruce, respectively. Aniline and Van Dyke brown stains also helped to reduce mass losses of spruce wood blocks. Mean termite mortalities resulted in a similar trend with mass loss findings indicating that tannin stained Scots pine and Spruce significantly increase termite mortalities while the hardwood species showed no changes in mortality rates with an exception of chemical stain treated Chestnut sapwood (Table 3).

Table 3. Mean mortality [M (\%)] of stained woods after exposure to Coptotermes formosanus for 3 weeks.

\begin{tabular}{|c|c|c|c|c|}
\hline \multirow{2}{*}{ Treatments } & \multicolumn{4}{|c|}{ Wood species } \\
\cline { 2 - 5 } & Beech & Chestnut & Scots pine & Spruce \\
\hline Control & $11,8(7,13) \boldsymbol{a}$ & $23,0(1,67) \boldsymbol{b}$ & $9,3(2,00) \boldsymbol{a}$ & $15,8(6,30) \boldsymbol{a}$ \\
\hline Aniline & $12,4(4,68) \boldsymbol{a}$ & $27,3(0,67) \boldsymbol{c}$ & $13,0(1,00) \boldsymbol{b}$ & $17,3(1,77) \boldsymbol{a}$ \\
\hline Chemical & $16,7(5,46) \boldsymbol{a}$ & $19,7(1,67) \boldsymbol{a}$ & $25,3(2,00) \boldsymbol{c}$ & $32,4(2,04) \boldsymbol{b}$ \\
\hline $\begin{array}{c}\text { Van Dyke } \\
\text { brown }\end{array}$ & $12,7(1,77) \boldsymbol{a}$ & $25,0(0,33) \boldsymbol{b}$ & $11,7(1,67) \boldsymbol{a} \boldsymbol{b}$ & $13,8(0,39) \boldsymbol{a}$ \\
\hline
\end{tabular}

mean of 5 specimens - numbers in parentheses are standard deviations

*means within each column followed by the same letter are not significantly different, $\mathrm{p}<0.05$ (Duncan's test).

Since percentage mass loss may vary due to density differences in wood species when exposed to a fixed number of termites, wood consumptions rates were also taken into account (Table 4).

Table 4. Mean consumption rate $[\mathrm{CR}$ ( $\mu \mathrm{g} /$ termite/day)] of stained woods after exposure to Coptotermes formosanus for 3 weeks.

\begin{tabular}{|c|c|c|c|c|}
\hline \multirow{2}{*}{ Treatments } & \multicolumn{4}{|c|}{ Wood species } \\
\cline { 2 - 5 } & Beech & Chestnut & Scots pine & Spruce \\
\hline Control & $87,3(15,05) \boldsymbol{a}$ & $21,6(6,30) \boldsymbol{a}$ & $64,4(1,83) \boldsymbol{c}$ & $301,8(50,32) \boldsymbol{b}$ \\
\hline Aniline & $82,1(16,65) \boldsymbol{a}$ & $25,6(3,59) \boldsymbol{a} \boldsymbol{b}$ & $52,3(5,04) \boldsymbol{b}$ & $50,7(7,76) \boldsymbol{a}$ \\
\hline Chemical & $58,5(22,38) \boldsymbol{a}$ & $36,2(7,91) \boldsymbol{b}$ & $11,4(1,51) \boldsymbol{a}$ & $53,7(7,52) \boldsymbol{a}$ \\
\hline $\begin{array}{c}\text { Van Dyke } \\
\text { brown }\end{array}$ & $76,2(32,72) \boldsymbol{a}$ & $33,8(6,60) \boldsymbol{a} \boldsymbol{b}$ & $70,0(0,45) \boldsymbol{d}$ & $84,1(10,07) \boldsymbol{a}$ \\
\hline
\end{tabular}

mean of 5 specimens - numbers in parentheses are standard deviations

*means within each column followed by the same letter are not significantly different, $\mathrm{p}<0.05$ (Duncan's test). 
Consumption rates of stained spruce sapwood were reduced $83 \%, 82,2 \%$ and $72,1 \%$ for the aniline, chemical and Van Dyke brown treatments, respectively. Similarly consumption rate was degraded from 64,4 to $11,4 \mu \mathrm{g} /$ termite/day for Scots pine sapwood when treated with chemical stain at $0,1 \mathrm{~kg} / \mathrm{m}^{2}$ retention level. While aniline treatment showed some reduction in the consumption rate for the same species, Van Dyke brown actually increased it. The visual representations are in line with the mass loss and termite mortality data, indicating that while the chemical stain treated softwood species display almost intact structures, the controls and other treatments were moderately or heavily damaged due to termite activity (Figure 2).
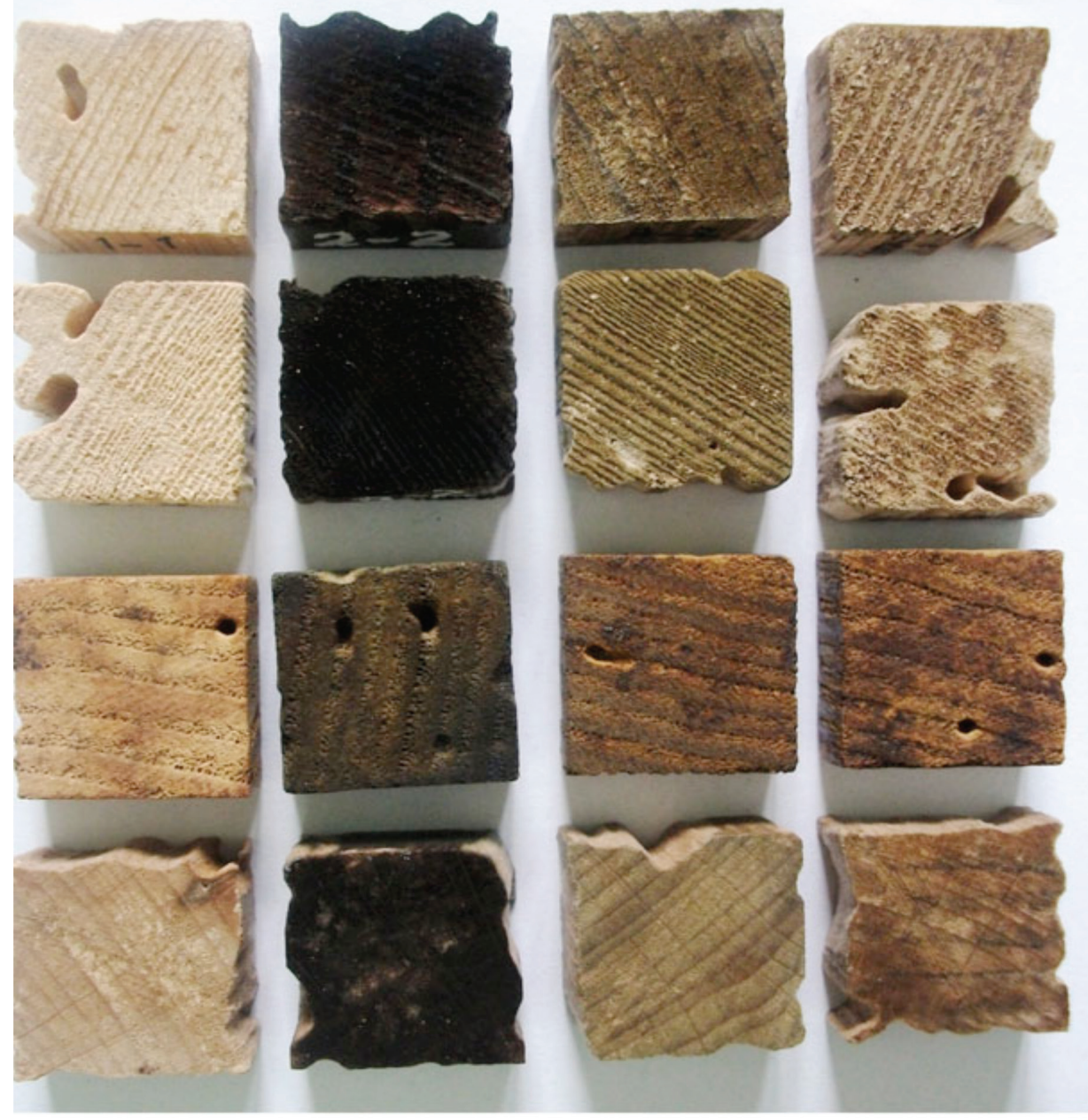

Figure 2. Visual observation of termite damage on some representative control and stained wood samples (Each row represent one species, from top to bottom; Pinus sylvestris (Scots pine), Picea orientalis (Spruce), Castanea sativa (Chestnut), Fagus orientalais (Beech), each column represents one stain treatment, from left to right; Untreated control, aniline, chemical, Van Dyke brown).

\section{CONCLUSION}

The results indicate that some wood stain chemicals significantly enhanced the resistance of softwood specimens against subterranean termite. When applied at $0,1 \mathrm{~kg} / \mathrm{m}^{2}$ retention levels, all three wood stain treatments significantly reduced mass loss and consumption rates and increased mortality rate in Spruce sapwood, while the chemical stain had the same effects on Scots pine sapwood. Staining of the two hardwood species, on the other hand, failed to enhance termite resistance properties. 


\section{ACKNOWLEDGEMENTS}

The first author extends his appreciation to RISH, Kyoto University for the invitation under the Visiting Professor program between April 1 and July 29, 2012.

\section{REFERENCES}

Arango, R.A.; Green III, F.; Hintz, K.; Miller, R. B. 2004. Evaluating the natural durability of native and tropical wood species against Reticulitermes flavipes. In proceedings, the $35^{\text {th }}$ IRG Annual Meeting in Ljubljana. IRG/WP 04-10539, the International Research Group on Wood Preservation, Stockholm.

Arango, R.A.; Green III, F.; Hintz, K.; Miller, R.B. 2006. Natural durability of tropical and native woods against termite damage by Reticulitermes flavipes (Kollar). International Biodeterioration and Biodegradation 57:146-150.

Esenther, G.R. 1977. Nutritive supplement method to evaluate resistance of natural or preservative treated wood to subterranean termites. Journal of Economic Entomology 70: 341-346.

Flexner, B. 2005. Understanding Wood Finishing, How to select and apply the right finish, The reader's digest Association, Inc., Pleasantville, New York.

Gardner, D. J.; Tascioglu, C.; Walinder, M. E. 2005. Wood composite protection. In Goodell, B.; Nicholas, D. D.; Schultz, T. P. (eds.) Wood Deterioration and Preservation: Advances in Our Changing World, American Chemical Society. Washington, D. C. pp: 399-419.

Ishiguri, F.; Maruyuma, S.; Takahashi, K.; Abe, Z.; Yokota, S.; Andoh, M.; Yoshizawa, N. 2003. Extractives relating to heartwood color changes in sugi (Cryptomeria japonica) by a combination of smoke-heating and UV radiation exposure. Journal of Wood Science 49:135-139.

Japan Wood Preserving Assoc. JWPA. 2001. Laboratory test method to evaluate effectiveness of termiticides for pressure treatment and performance requirements of the treated material. JWPS-TW-P-1. Japan Wood Preserving Association, Tokyo.

Newel, A.C.; Holotrop, W.F. 1961. Coloring finishing and painting wood. Chas. A. Benett Co. Inc., Peoria, Illinois.

Siau, J.F. 1995. Wood: Influence of moisture on physical properties. Department of Wood Science and Forest Products, Virginia Polytechnic Institute and State University, 227p.

Sonmez, A.; Budakci, M.; Delikan, A.B. 2003. Color changing with on the stained wood surface with wood stains. Gazi University Journal of Science 16(4):769-777.

Sonmez, A. 2005. Preparation and coloring, finishing on woodworking I. Gazi University, Technical Education Faculty, Ankara.

SPSS 19. 2010. Statistical Analysis Software, Version 19, Turkey.

Peralta, R.C.G.; Menezes, E.B.; Carvlho, A. G.; Aguiar-Menezes, E.L. 2004. Wood consumption rate of forest by subterranean termites (Isoptera) under field conditions. Rev Arvore 28:1-12.

Vazquez, G.; Gonzales-Alvarez, J.; Santos, J.; Freire, M.; Antorrena, S. 2009. Evaluation of potential applications for chestnut (Castanea sativa) shell and eucalyptus (Eucalyptus globulus) bark extracts. Industrial Crops and Products 29:364-370. 